\title{
El Grito del Ejército y La España Militar: dos ejemplos de prensa castrense
}

\section{El Grito del Ejército and La España Militar: two examples of military press}

\author{
Diego Cameno Mayo \\ dcameno@ucm.es \\ Universidad Complutense de Madrid \\ http://orcid.org/0000-0003-1204-6236
}

Fecha de recepción: 30-08-2020

Fecha de aceptación: 11-11-2020

\section{RESUMEN}

La prensa militar proporciona gran cantidad de información acerca de la situación del instituto armado de un país en un periodo concreto. Su interés radica en que son escritos por militares y para militares, permitiendo al lector conocer cuáles eran los temas que más preocupaban a los soldados del momento. Este trabajo pretende analizar unos periódicos concretos, ligados a la figura del capitán Eduardo Perrotte, quien los bautizó como El Grito del Ejército y La España Militar, publicados en un periodo determinado (la Regencia de Espartero, tras finalizar la Primera Guerra Carlista), buscando conocer la manera en que una parte del ejército se veía a sí misma y lo plasmaba por escrito para que todos lo leyesen, en un contexto de posguerra civil, en la que las tropas no se sentían cómodas con ciertas medidas del gobierno (muy criticado en estos periódicos) y con el tratamiento que recibían por parte de una sociedad a la que habían defendido, derramando su sangre, entre 1833 y 1840.

Palabras clave: ejército español, prensa militar, Perrotte

Topónimos: España, Madrid

Período: siglo XIX

\section{ABSTRACT}

The military press provides a great deal of information about the situation of the Army at any given time. Its interest lies in the fact that it is written by soldiers and for soldiers, alerting the reader to the issues that most concerned the soldiers of the moment. This work analyses two specific newspapers, linked to the figure of Captain Eduardo Perrott: El Grito del Ejército and La España Militar, published during a specific period (the Regency of Espartero, after the First Carlist War). With a view to discovering how part of the Army saw itself in a post-civil war context, in which troops did not feel comfortable with certain government measures (the target for much criticism in these newspapers) or with the treatment they received from a society that they had defended, shedding their blood, between 1833 and 1840. 
Key words: Spanish Army, military press, Perrotte

Toponyms: Spain, Madrid

Period: $19^{\text {th }}$ century

\section{INTRODUCCIÓN}

En el año 1840 concluía la primera de una serie de guerras civiles que lastrarían gravemente a nuestro país durante un siglo. Esta, más conocida como Primera Guerra Carlista, dejaba a los militares en un papel protagonista al iniciarse la década de los 40 del siglo XIX. No en vano, el general que más fama y prestigio había obtenido en la campaña, don Baldomero Espartero, accedería pronto a un puesto tan elevado como la Regencia del país. La preponderancia militar y la inauguración de una época gobernada por el progresismo, más permisivo con ciertas libertades, como la de prensa, invitaban a los militares a fundar periódicos que expresasen sus ideas y opiniones, defendiesen sus posturas o difundiesen tanto entre la población como entre los propios soldados, las labores y tareas que realizaban los ejércitos. Ciertamente esto fue así, ya que entre 1841 y 1843 se publicaron hasta una docena de medios militares, la mayoría de ellos -como es el caso de los que aquí se estudian- de corta vida.

No obstante, el periodo iniciado en mayo de 1841 pasó rápidamente de la ilusión y la esperanza de cambio a la desunión y el fracaso. Los progresistas, que sobre el papel eran los partidarios de Espartero, pronto se dividieron y, en el otro extremo, la oposición de los moderados no daría tregua en ningún momento. A Espartero se le acumularon los problemas desde el comienzo: la formación de un gabinete con apoyos suficientes para poder gobernar o la tutela de las princesas Isabel y Luisa Fernanda fueron los primeros quebraderos de cabeza para el duque de la Victoria ${ }^{1}$. Sus enemigos tampoco tardaron mucho en minar la posición del Regente y su gobierno. En octubre de 1841 aprovecharon la división en el seno del ejército e iniciaron una sublevación con el apoyo de generales de la talla de Leopoldo O'Donnell, Manuel Gutiérrez de la Concha, Ramón María Narváez o Diego de León. El objetivo era secuestrar a Isabel y restaurar a María Cristina como regente. La conspiración fracasó y los generales capturados (entre ellos el propio Diego de León) fueron fusilados, un acontecimiento que dividió más al ejército y restó muchos apoyos (incluidos militares) al "déspota" Espartero². Su popularidad, aunque aún se mantenía en cotas elevadas, empezaba a decrecer. El otoño de 1842 fue más complicado: en octubre se revisó la ley de prensa, un acontecimiento directamente relacionado con el tema de este trabajo y que será tratado más adelante, y en noviembre tuvo lugar el tan célebre como lamentado bombardeo de Barcelona. Cuando Espartero regresó a Madrid de la Ciudad Condal, el entusiasmo popular que le había acompañado desde años anteriores parecía haber desaparecido. Cada vez más aislado, el Regente tuvo que soportar la división de los progresistas, los ataques de sus enemigos, que ya contaban con importantes sectores del ejército, y la oposición de casi toda la prensa ${ }^{3}$. Así se llegó a junio de 1843, cuando los generales Juan Prim y Lorenzo Milans del Bosch iniciaron un levantamiento militar que, tras

1 Véase A. Shubert, Espartero, el Pacificador, Barcelona, Galaxia Gutenberg, 2018, pp. 251-257.

2 Ibídem, pp. 268.

3 En París, sus enemigos crearon la Orden Militar Española, con importantes oficiales del ejército en sus filas. Según Shubert, estos se hicieron con la dirección del periódico El Archivo Militar, que emplearon para continuar su hostigamiento a Espartero. Ibídem, p. 289. 
contar con el apoyo de la exregente María Cristina e importantes generales enemigos de Espartero (Narváez y O'Donnell entre ellos) acabaron definitivamente con la Regencia del duque de la Victoria.

Con esta breve síntesis del periodo, queda patente la relevancia de los militares durante el mismo. Espartero, convertido en símbolo por sus éxitos en la guerra, accede a la más alta magistratura del Estado. Él mismo se rodeó de correligionarios (los llamados, despectivamente, "ayacuchos") y, sus rivales, no podrán derribarle hasta que no cuenten con el suficiente número de efectivos militares. Los principales acontecimientos, aquellos que minaron su popularidad y los que hicieron tambalear su posición hasta hacerle caer, estuvieron protagonizados por miembros del ejército, bien fracasando y convirtiéndose en mártires (Diego de León) o bien triunfando y ostentando, con ello, el poder, durante una década (Ramón María Narváez).

La importancia de estudiar periódicos de tipo militar para conocer la situación y el pensamiento del ejército en cualquier momento tiene un doble interés: por un lado, porque estos medios podían crear estados de opinión, advirtiendo cuestiones que podían pasar desapercibidas para los lectores o reforzando sus convicciones en ciertos temas. Por otro lado, eran escritos por los propios militares, lo que puede dar una idea acerca de cómo ellos se veían a sí mismos, denunciando qué aspectos se deberían mejorar o, cuando menos, expresando y mostrando al público en general cuál era el estado que ellos percibían y qué sugerencias tenían para la milicia armada.

Sin embargo, pese al interés de este tema, no disponemos de muchas obras que analicen la prensa militar durante el reinado de Isabel II, siquiera de forma breve, como sí existe para la Restauración o para épocas anteriores ${ }^{4}$. No obstante, son muchas las obras que hacen referencia, de manera sucinta, a los periódicos que los militares de este periodo empleaban para expresarse. Stanley G. Payne llamaba la atención del lector, negando que se tratase de una prensa oficial del ejército sino más bien de órganos de expresión de distintos grupos asociados a las distintas ramas militares. A consecuencia de esto, afirma este autor, las publicaciones eran breves, efímeras y sus consecuencias bastante lesivas para el instituto armado ya que lo único que consiguieron fue distraer a los militares y, aún peor, dividirlos 5 .

No obstante, pese a la escasa presencia en la historiografía de un análisis exhaustivo de la prensa militar, no faltan especialistas en este tipo de materias. El más importante es Mariano Aguilar Olivencia, ${ }^{6}$ a quien el reconocido historiador militar de nuestro siglo XIX, Fernando Fernández Bastarreche, agradecía sus estudios en este ámbito, allá

4 F. J. Vanaclocha Bellver, Prensa político-militar y sistema de partidos en España (1874-1898), Madrid, Fundación Juan March, 1981. Otro ejemplo es el monográfico sobre prensa militar de El Argonauta español: "La Presse militaire. Naissance et évolution d' un genre", 10, (2013), con estudios para la prensa de la época de la Guerra de la Independencia (1808-1814) o del siglo XX y tan solo uno dedicado a los medios carlistas existentes en el Maestrazgo entre 1836 y 1840 en el marco de la Primera Guerra Carlista (1833-1840). P. Rújula, "Journalisme militaire pendant la premiére guerre carliste: le Boletín del Real Ejército de Aragón, Valencia y Murcia", El Argonauta español, 10, (2013).

5 S. G., Payne, Los militares y la política en la España Contemporánea, París, Ruedo Ibérico, 1968, p. 13.

6 M. Aguilar Olivencia, "Los orígenes de la prensa militar española", Reconquista, 339 (1978), pp. 58-59; M. Aguilar Olivencia, "Prensa de otros tiempos: Almanaque del Guardia Civil", Vida Benemérita, 8, (1979), pp. 31-33; M. Aguilar Olivencia, "Prensa de las clases pasivas en las Fuerzas Armadas", Tierra, Mar y Aire, 118, (1979), pp. 25-26; M. Aguilar Olivencia, "Ese gran desconocido en España (I). El periodismo militar", Diario 16, (1979); M. Aguilar Olivencia, "Ese gran desconocido en España (y II). El periodismo militar", Diario 16, (1979); Aguilar Olivencia, "Historia del periodismo español. Escasas fuentes de investigación al tratar de periodismo militar”, Ejército, (1980). 
por 1978, afirmando que se trataba de "uno de los temas inexplorados que mayor importancia reviste"7.

Ya en el siglo XXI, la prensa militar ha sido tratada, aunque siempre como algo complementario, en diversos trabajos de temática militar. Pablo González-Pola de la Granja apenas dedica cuatro páginas a este tema, mientras que Enrique Silvela Díaz-Criado basa su análisis en una tesis doctoral que dedica más espacio a este tema: el trabajo de Fernando Pinto Cebrián ${ }^{8}$. Este último realiza un breve análisis de la prensa militar española publicada a lo largo del Ochocientos, dividiendo las publicaciones por su temática y, dentro de esta, siguiendo un esquema cronológico. Pinto comienza por las revistas y periódicos de tipo político, desde 1808 (con la invasión francesa) hasta final de siglo. Tras el análisis de las obras políticas se centrará en aquellas de carácter profesional como los memoriales. Este autor, siguiendo las tesis de Payne y de José Luis Herrero, también considera que los periódicos sirvieron como "tribunas ideológicas" de las facciones internas del ejército y, más aún, fomentaron la intervención en política de los militares ${ }^{9}$. La prensa militar podía dividirse en tres ámbitos: recopilaciones y colecciones legislativas, periódicos político-militares y prensa técnica. El problema que tenían estas últimas es que, si bien buscaban acercar temas complejos a todas las clases militares, en realidad no llegaban más que a un público bastante reducido y, generalmente, especializado.

No obstante, la prensa objeto de análisis en este artículo pertenece al segundo de los tres ámbitos. Comienza a publicarse bajo el mandato del general Baldomero Espartero cuando, según Pinto Cebrián, "se multiplica la prensa castrense que, considerándose portavoz del colectivo militar, cobra marcado carácter político, sin perder su función formativa"10. Precisamente, El Grito del Ejército de Eduardo Perrotte será citado como ejemplo de este tipo de prensa.

Un aspecto que citan la mayoría de trabajos que tratan las publicaciones militares es el del número de periódicos que se pusieron en circulación. Payne habla de no menos de 34 publicaciones; el especialista en prensa decimonónica, Antonio Checa Godoy afirma, con Aguilar Olivencia como referencia que, durante el Sexenio Democrático (1868-1874), "apogeo de la prensa militar", había 52 periódicos militares en circulación ${ }^{11}$. Según lo publicado por este mismo autor, ${ }^{12}$ parece que la cifra que ofrece Pinto Cebrián -siguiendo a Barado- sea una de las más plausibles. Este autor afirma que, entre 1812 y 1888 se publicaron 114 periódicos de temática militar, aunque algunos, como los que van a ser analizados, no gozasen de una larga andadura ${ }^{13}$. Tanto El Grito del Ejército como La España

7 F. Fernández Bastarreche, El Ejército español en el siglo XIX, Madrid, Siglo XXI, 1978, p. 23.

8 P. González-Pola de la Granja, La configuración de la mentalidad militar contemporánea y el movimiento intelectual castrense. El siglo crítico 1800-1900, tesis doctoral, Madrid, Universidad Complutense, 2002, pp. 76-80; E. Silvela Díaz-Criado, El proceso de profesionalización del Ejército en España: El Cuerpo de Estado Mayor, 1810-1932, tesis doctoral, Madrid, Universidad Nacional de Educación a Distancia, Instituto Universitario General Gutiérrez Mellado, 2015, pp. 355-356; F. Pinto Cebrián, Ejército e historia. El pensamiento profesional militar español a través de la literatura castrense decimonónica, tesis doctoral, Universidad de Valladolid, 2011, pp. 167-177.

9 F. Pinto Cebrián, Ejército e historia..., p. 167.

10 Ibídem, p. 169.

11 A. Checa Godoy, El ejercicio de la libertad. La prensa española en el Sexenio Revolucionario (1868-1874), Madrid, Biblioteca Nueva, 2006, p. 80.

12 A. Checa Godoy, Censo de la prensa española en los inicios del Régimen Liberal (abril 1833-julio 1843) y relación de periodistas y fuentes, Sevilla, Padilla, 2018; A. Checa Godoy, Censo de la prensa española editada durante el reinado de Isabel II (1843-1868), Sevilla, Padilla, 2018.

13 Pinto Cebrián, Ejército e historia..., p. 167. 
Militar serán dos de las publicaciones más importantes de este periodo. Su postura política, cada vez más en contra de la gestión de los gobiernos esparteristas, provocará el fin de estos medios, acompañando a otros como El Archivo Militar, muy similar a estos y con los que competirán ( $y$ entrarán en alguna polémica), aunque compartiesen el mismo final: la desaparición.

\section{EL GRITO DEL EJÉRCITO (1841)}

Este medio, dirigido por el capitán graduado de Caballería, Eduardo Perrotte ${ }^{14}$, nacía por la escasez existente de órganos de prensa que expresasen las necesidades del ejército. Para solucionar esto llegaba este periódico, tribuna para exponer y defender los derechos de los militares. Editado en Madrid, se publicará dos veces al mes a través de la Imprenta Yenes. Estará estructurado en varias secciones: una primera parte en la que se presentaban artículos de denuncia de la situación del ejército o información general sobre el mismo. En este bloque los artículos solían ir firmados, siendo el nombre del coronel Luis Corsini, escritor militar que ascendió al generalato en el Arma de Caballería, uno de los más repetidos. ${ }^{15}$ La segunda parte se dedicaba a comentar noticias, publicaciones de otros medios, posibles reformas que se discutían para el Ejército o nombramientos y ascensos, aunque, en algunos números, se podían leer episodios históricos del ejército español, especialmente centrados en la guerra carlista. Además, se ofrecía al lector información técnica sobre cuestiones militares, recomendaciones de obras de obligada lectura para el soldado que desease mejorar su instrucción o miradas al extranjero para conocer la situación de otros ejércitos, aunque estas últimas eran más escasas. Tampoco se olvidaban de proponer reformas y cambios que acabasen con los males que, según su opinión, aquejaban al ejército, siendo los más repetidos la profusión de grados, ascensos y condecoraciones, el excesivo presupuesto (mal gestionado) para el ejército o la visión negativa que se tenía del instituto armado entre la población española de los primeros años de la década de 1840.

En el primer número ${ }^{16}$, correspondiente al 1 de mayo de 1841, dejaba bien claro que no solo se dedicaría a defender los intereses del ejército, a exigir y velar por el cumplimiento de reformas militares que mejorasen la institución, también traería artículos interesantes para el militar y hazañas pasadas e incluso permitiría que cualquier militar escribiese columnas en el medio. El victimismo, provocado por un olvido sistemático de la sociedad del papel que jugaba en ella el ejército, será recurrente desde el primer momento. Así

14 Autor de un opúsculo titulado de igual forma que el medio periodístico: el Grito del Ejército, Madrid, Imprenta de Cruz González, 1841. En ella ya denunciaba el poco reconocimiento que se daba al ejército tras haber sido el adalid de la libertad de la patria en tantas ocasiones. Posteriormente trabajó en medios de relevancia como La Revista Militar.

15 Aunque encontraremos otros notables como Rafael Primo de Rivera, Corsini será de los más activos. Este militar nacido en París en 1791 y fallecido en Madrid en 1878 se dedicó profusamente a la literatura, siendo autor de obras de temática no exclusivamente militar. Dentro de los escritos sobre las armas, destacó como colaborador en diferentes medios hasta figurar como único redactor del medio El Estandarte (1845) en el que abordaba cuestiones técnicas, administrativas, legislativas e históricas sobre el ejército, siempre persiguiendo un fin didáctico. Véase P. Gutiérrez de Quijano, Biografía de don Luis Corsini y Fontaine, Madrid, Gráfica Universal, 1933.

16 Aunque previamente se habían publicado dos cuadernos titulados de la misma manera. Estos están fechados en marzo y abril de 1841 y ya dejan ver la dirección que tomará el nuevo medio: el ejército, héroe y querido en la guerra, era olvidado en la paz, obligado a vivir en la miseria, a recortar en él. En la guerra todo el mundo le quería pero después de cumplida su misión todos le relegaban a un segundo plano. Aunque denote cierto victimismo, El Grito del Ejército no dejará nunca de denunciar esa situación y hará repetidos llamamientos para cambiarla, remarcando las virtudes de los soldados y su papel fundamental en la sociedad. 
lo dejaba patente el primer artículo “¿Quién vive?” en el que se mostraba a un ejército que, después de salvar a la patria, caía en el olvido, sin recompensa por sus sacrificios y sumido en la miseria ${ }^{17}$. Esto último es interesante porque será reiterativo en estas páginas: El Grito del Ejército mostrará siempre una institución armada que sobrevive a duras penas por falta de dinero y alimentos. En "Un grito hasta el cielo" se comentaba un suceso entre oficiales del regimiento de Mallorca y el ministro de Hacienda. Aquí se retrataba un ejército (especialmente la tropa y hasta los oficiales subalternos) muerto de hambre, con el perjuicio que esto tenía para, entre otras cosas, mantener la imprescindible disciplina ${ }^{18}$.

No hay que adentrarse mucho en este medio para descubrir la primera crítica al gobierno, en este caso por la lentitud en la aplicación de las reformas militares. Sin embargo, la censura no se detenía ahí y continuaba atacando a los políticos por la proposición de ley, leída en el Congreso, acerca de las recompensas militares ${ }^{19}$. Se quería ascender a todos los sargentos y oficiales (hasta teniente coronel) que hubiesen combatido al lado de Isabel II en la última guerra, es decir, la I Guerra Carlista de 1833-1840. También concedía una cruz de distinción a todos (ya fuesen del Ejército, Marina, Milicia Nacional...) que hubiesen participado en el conflicto; se les aumentaría la paga y se les darían tierras. Este medio agradecía el gesto pero pedía reflexión, especialmente en el punto de los ascensos de grado. Los grados honoríficos, que no se traducían en ascensos de empleo, iban en contra de la disciplina y eran inútiles para excitar "las virtudes militares". Además, concedérselo a todos carecía de sentido puesto que era igual que no dárselo a nadie.

Los redactores de este medio se mostraban en contra de los grados en el ejército y de los supernumerarios (o excedentes), a los que tildaban de "cáncer". Había que acabar con ambos. Por otro lado, aumentar el número de oficiales en un ejército en el que ya sobraban no tenía sentido. La profusión de ascensos era una equivocación tan grande como la prodigalidad de condecoraciones, un abuso iniciado décadas atrás, hasta el punto que era difícil encontrar un militar que no adornase su pecho con una insignia, mermando el prestigio de todas ellas, llegando al extremo que el público las veía con indiferencia, cuando debían ser todo lo contrario ${ }^{20}$. No estaban de acuerdo con esas medidas y pedían que se tratase bien al ejército (pagando lo que le debían o recompensando a inválidos y viudas, por ejemplo) antes de meterse en otras cuestiones ${ }^{21}$.

No sería esta la última vez que entrasen a comentar aquello que les incumbía dentro de las paredes del Congreso, más bien al contrario; este periódico siempre demostró estar muy al tanto de lo que se debatía en las Cortes acerca del ejército. Luis Corsini haría un comentario acerca de la ley de retiros aprobada en el Congreso, ley que, dicho sea de paso, no agradaba mucho a los redactores de este medio ${ }^{22}$. No les gustaba nada lo que estaba

17 El Grito del Ejército, 01 de mayo de 1841, pp. 6-13.

18 Ibídem, pp. 20-25. Las peticiones de aumento de sueldo para mejorar las condiciones de vida de los militares serán constantes en este periódico: "Sueldos", El Grito del Ejército, 01 de junio de 1841, pp. 1-9 o "Adjuración lastimera", El Grito del Ejército, 01 de julio de 1841, pp. 4-8, son algunos ejemplos de ello.

19 El Grito del Ejército, 20 de mayo de 1841, pp. 1-20. Se llegó a crear una comisión de Recompensas militares encargada de redactar dicha ley pero en agosto de 1841 se seguía discutiendo en el Congreso sobre ella, ante la impaciencia de aquellos a los que se prometió una recompensa tras la guerra. Véase DSSC, Congreso de los Diputados, núm. 141, 17-08-1841, pp. 3174-3176.

20 Una cuestión que denunciaban otros medios: El Archivo Militar. 13 de abril de 1842, pp. 1-3; 14 de mayo de 1842, pp. 1-3; 02 de noviembre de 1842, pp. 2-3; 05 de noviembre de 1842, pp. 1-2; 25 de marzo de 1843, pp. 1-2; 19 de abril de 1843, pp. 1-3.

21 El Grito del Ejército, 20 de mayo de 1841, pp. 1-20.

22 El Grito del Ejército, 01 de julio de 1841, pp. 11-19. La discusión sobre dicha ley comenzó en el Congreso en el mes de mayo y se prolongaron varios meses hasta su aprobación y publicación en la Gaceta, núm. 2498, 
haciendo el gobierno en materia militar porque no se ponían remedios serios. Todo esto no era óbice para que no se aplaudiesen medidas que consideraban acertadas como la revisión de las ordenanzas del ejército, aunque pedían que se tuviese en cuenta a oficiales, subalternos y hasta sargentos jóvenes, porque a ellos también les afectaba la cuestión y su voz era igual de importante que la de los viejos veteranos ${ }^{23}$.

Tampoco dejarán pasar la ocasión de escribir a las Cortes por si estas querían la opinión de los militares. En un texto sobre la importancia del ejército y la necesidad de que fuese permanente, recopilaban sus principales posiciones en cuanto a la institución armada: se quejaban del inmovilismo que primaba en la legislación militar y pedían reformas, protestaban por la desconsideración e incomprensión en que vivían, por el uso arbitrario que los partidos políticos hacían de la institución armada, por lo mal gestionado que estaba el -exagerado- presupuesto de Guerra y por las penosas condiciones de vida que sufrían día a día, mientras se sostenía una oficialidad sobredimensionada hasta el extremo. Este texto decía que para la defensa de la Patria, para su mantenimiento, fortaleza, independencia y libertad hacía falta que hombres renunciasen a una vida plácida, al dinero, a la familia y se sometiesen al riesgo de la guerra, de la muerte. Esta abnegación merecía algo a cambio: el país debía cuidar bien a sus militares. Esto no sucedía y gran parte de culpa la tenía el gobierno. Todos los ámbitos del país avanzaban, se reformaban, mejoraban,

mientras nosotros, pobres militares, seguimos rejentados [sic] por las Ordenanzas de Carlos III, torturados por el beneplácito y la arbitrariedad, saqueados por el nepotismo, y clamando en vano por la legalidad, la publicidad y la supremacía del talento y del verdadero mérito sobre la bajeza y la adulación.

Las tropas también tenían derechos y para conocerlos había que vivir en la institución, no en ese ejército "de fajas y de bordados que solo conoce de la milicia el polvo de las paradas", sino el ejército de a pie, el que sufría los rigores de la vida militar. La milicia era instrumento de los partidos, siempre maltratada, sin muestras de gratitud, mirada con indiferencia, incomprendida y calumniada. No pedían privilegios sino derechos. Los políticos solo hablaban del exagerado presupuesto del ejército y era verdad, pero era necesario acabar con los abusos, ver dónde se iba ese dinero y ponerle freno. Porque ese presupuesto se malgastaba, no iba donde debía y el pueblo miraba mal al ejército porque era una pesada carga para ellos, cuando el despilfarro no era culpa de los militares. El ejército era la primera piedra para la regeneración de la Patria y aunque había corrupción en otras partes, aquí era más sangrante, preocupante e importante.

Había 100.000 hombres y 630 generales, entre 50 ó 60 regimientos y unos 800 coroneles, esto no podía sostenerse de ninguna manera. Ese número excesivo causaba muchos males al ejército y a la sociedad, malgastando recursos. El soldado y el oficial vivían miserablemente, pasaban hambre, tenían que mendigar y eso no se podía tolerar ${ }^{24}$.

No obstante, estas críticas no le saldrían gratis a Perrotte (y no sólo a él), como dejó patente la circular del ministro de la Guerra, Evaristo San Miguel, en la que buscaba limitar,

19-08-1841, p. 2. DSSC, Congreso de los Diputados, núm. 53, 27-05-1841, p. 972 y núm. 54, 28-05-1841, pp. 991-992.

23 El Grito del Ejército, 17 de julio de 1841, pp. 10-15.

24 El Grito del Ejército, 15 de noviembre de 1841, pp. 201-207. La segunda y tercera parte de este artículo, en el que incidían en más reformas, como acabar con el desmesurado presupuesto para Guerra, nueva legislación militar acorde a los tiempos y que dejase clara la política de ascensos evitando así la macrocefalia del ejército, podía leerse en las entregas sucesivas: 01 de diciembre de 1841 y 20 de diciembre de 1841. 
cuando no censurar, la libertad de prensa de los militares ${ }^{25}$. En "El señor S. Miguel y su circular reservada" protestaban porque decían que se estaba intentando "ahogar" a Perrotte, impidiéndole escribir y publicar en su propio medio. Denunciaban un ataque a la libertad de prensa que no existía hasta que se dieron cuenta de que este periódico hostilizaba demasiado al gobierno en sus escritos e intentaban impedir que siguiese publicando. Abrían el debate sobre si los militares podían o no acogerse a la libertad de prensa. Evidentemente, este medio defendía que $s^{26}$. La cosa no quedó ahí y, en los números siguientes, continuaron atacando a San Miguel por haber intentado coartar la libertad de prensa a los militares. El Ministro se defendía asegurando que medios como El Grito del Ejército minaban la disciplina y promovían la insubordinación, cosa que este medio negaba ${ }^{27}$. El 15 de septiembre de 1841, varios oficiales, que no se destacaban por su militancia política, llegaron a firmar una carta en la que se unían al rechazo de la circular de San Miguel. No podían creer que el Ministro les prohibiese expresar sus pensamientos. Sentían su honor ultrajado y lo veían como un ataque al ejército, a la Constitución y a las leyes del pueblo, esas que la milicia defendería siempre, ya que esa era su misión ${ }^{28}$.

Sin embargo, si había un tema recurrente en este medio, más que criticar las medidas del gobierno en materia militar, más que la defensa de los intereses del ejército, más que la denuncia de la mísera condición de vida de los soldados, esa era un actitud que puede ser calificada de victimista: el ejército había dado todo, hasta su vida, por la Patria y, lejos de ser recompensado por ello, era olvidado, incomprendido, despreciado. Ya se ha citado algún ejemplo en las páginas anteriores, pero es momento de analizar más ejemplos de este sentimiento de los redactores de este medio. En "De la desconsideración del uniforme", afirmaban que, antiguamente, el militar era tenido en gran estima por sus conciudadanos y, precisamente, eso era lo que pretendía, llegando a dar la vida por ellos. Pero esto ya no era así y los periodistas de este medio no entendían por qué; si los militares se enfrentaban a los mismos peligros que antes y su vida era igual de dura, su consideración debería seguir siendo notable entre la sociedad. La respuesta podía estar en el dinero. A mediados del siglo XIX el dinero primaba por encima de todo, hasta del honor o la virtud. No obstante, los militares también tenían culpa: hechos como el desprestigio de las insignias por su abuso durante años no ayudaban en absoluto. Antiguamente, el uniforme era distintivo

25 Lo cierto es que la orden venía de más arriba; era el propio Regente el que mandaba a los inspectores y directores de las armas que prohibiesen a sus subordinados publicar textos o periódicos en los que se criticara o censurara al Gobierno y, además, ordenaba que se vigilase a aquellos sujetos que se dedicaban a publicar ese tipo de escritos. El texto se refería los oficiales que afirmaban «defender los intereses del mismo ejército» cuando en realidad no eran más que críticas al Gobierno que podían ser usadas por sus enemigos para "escitar [sic] rivalidades", con el peligro que eso suponía para el orden. Espartero reconocía que los españoles podían expresar y publicar sus ideas pero los militares no podían emplear ese derecho para fomentar la insubordinación e indisciplina. Orden del 6 de agosto de 1841. Archivo Militar: Colección de las leyes, reales decretos, órdenes, reglamentos, circulares y resoluciones generales espedidas [sic] por el Ministerio de la Guerra, 1841, pp. 189-190.

26 El Grito del Ejército, 17 de julio de 1841, pp. 8-18. Perrotte no fue el único que vio su carrera afectada por esta discusión con el Ministro, su colega de profesión, Antonio Vallecillo, responsable de El Archivo Militar, también sufrió las consecuencias de criticar al gobierno en la prensa. Véase El Archivo Militar. Sección Política, 13 de septiembre de 1841, p. 4 y 7 de septiembre de 1841, pp. 1-4, y El Grito del Ejército, 17 de julio de 1841, pp. 28-32.

27 Las entregas del 15 de septiembre y del 1 de octubre de 1841 aparecerían monopolizadas por el asunto San Miguel. A las acusaciones de subvertir el compañerismo, sembrando discordias y queriendo enfrentar al ejército entre sí y contra el gobierno, este medio se defendía asegurando que su misión era defender los intereses del ejército y no a atacar al gobierno.

28 El Grito del Ejército, 01 de octubre de 1841, pp. 102-105. 
del militar, ahora otras carreras no militares, como policías o empleados de oficinas, se habían apropiado de él. Desde este medio se pedía que no se confundiese al militar con los otros, porque las charreteras del uniforme militar se compraban con sangre, no con dinero. Además, que chiquillos que no sabían mandar las mostrasen con ostentación hacía un flaco favor al ejército. Por tanto, la antigüedad no debía contar desde los 12 años ni se debía ser oficial a los 16, la edad debía situarse en 18 años y se tenía que haber demostrado valía para el empleo 29 .

El victimismo seguía en "Una historia y un cuento" que, elocuentemente, empezaba de la siguiente manera: "Pobre ejército! Vas á tener la misma suerte que una magnífica guitarra mía que cayó el otro día en garras del mico de mi vecina". En él se hablaba de la posible supresión del ejército vistas las medidas que se estaban adoptando sobre licenciamiento de tropa ${ }^{30}$.

\section{LA ESPAÑA MILITAR (1842-1843)}

El 20 de diciembre de 1841 el lector de El Grito del Ejército recibía la última entrega de este medio. No obstante, esto no iba a frenar a Eduardo Perrotte que, el 1 de febrero de 1842 volvía a la carga con un nuevo medio: La España Militar (Imprenta de Alegría y Charlain e Imprenta de José Cosme de la Peña). Entre su equipo de redactores y colaboradores se encontraban distinguidos nombres de la milicia: el ya citado Luis Corsini, el general Juan Van-Halen, el general Francisco Serrano, el coronel Salvador Valdés, el coronel Francisco Luján, el brigadier Joaquín Moreno de las Peñas y el comandante Juan Guillén Buzarán.

El propio medio ofrecía su objetivo: difundir, de forma amena, la instrucción y los adelantos que afectasen a todas las ramas del ejército. A su vez, deseaba contribuir a la moralidad de las tropas y darles publicidad. El periódico, editado en Madrid, vería la luz cada diez días (como normal general). Estaba formado por tres pliegos y dividido en cuatro secciones: didáctica, histórica y literaria, oficial, cronical. La primera de ellas contaba con artículos teóricos, de filosofía, científicos, de interés para el ejército y de actualidad. La segunda relataba hazañas y eventos pasados, ocurridos hasta la última campaña (incluida) pero también artículos de costumbres o literarios. Estas secciones se acompañarían frecuentemente con planos, dibujos, tipos de uniforme, ilustraciones y demás, con la finalidad de ayudar a comprender el texto. La tercera se componía de Reales Órdenes, Decretos, circulares del Ministerio, recompensas, ascensos, promociones, etc. La última se nutriría de noticias relacionadas con el ejército, tanto nacionales como del extranjero. Así serían los primeros pliegos pero había otro, suelto, que se llamaría «Biblioteca Militar», con cuestiones que consideraban útiles para el ejército porque se componía de obras y bibliografía imprescindible para el militar. Había obras de César, Tucídides, Maquiavelo, Ramonet, San Miguel...

La continuidad con la anterior publicación quedaba patente desde el principio, no solo por las ideas que tenían acerca de la política -tendiendo hacia un marcado conservadurismo y de oposición a Espartero-y el ejército, sino porque ellos mismos se reconocían sucesores de la publicación censurada. Así, lo primero que decían era que el ejército seguía "ahogado por la influencia del nepotismo". Todos fluían, todos mejoraban y ascendían (labradores, tenderos, comerciantes...), pero el ejército se mantenía inmóvil, no prosperaba. Las tropas estaban a merced del ministro de la Guerra, se movían entre la indiferencia del resto de la sociedad y clase política y solo la prensa militar podría ayudar a mejorar su situación,

29 El Grito del Ejército, 01 de junio de 1841, pp. 18-26.

30

El Grito del Ejército, 17 de julio de 1841, pp. 6-9. 
pero esta no era vista con buenos ojos por parte de las autoridades (justo todo lo contrario de lo que debería hacer un hombre inteligente, que sería cuidar la prensa militar igual que la civil). Como se ha visto, el anterior medio de Perrotte tan solo duró unos meses (y publicó dieciséis números), acosado por coerciones y rodeado de hostilidad; por eso llegaba esta nueva publicación, como un "fénix que sale de sus cenizas", con una declaración de principios similar a la de medios como El Archivo Militar: defender al ejército de cualquiera que fuese en su contra y respetar y fomentar la disciplina ${ }^{31}$.

Este primer número ya dejaba patente ese sentimiento de aislamiento de los militares respecto al resto de la sociedad y protestaba por la escasez de los sueldos de los soldados. Tan solo un número después, ya criticaban al gobierno por no acabar con el exceso de oficiales generales del ejército español ${ }^{32}$. Un ejemplo más de que tan solo cambiaba el nombre de la publicación.

El mérito, que si bien había aparecido como telón de fondo en algún artículo del anterior medio, era ahora el protagonista de un texto firmado por Luis Corsini. Este oficial decía que el favor había existido siempre y que siempre se había adelantado al mérito. Uno estaba en las antípodas del otro. Exponía cómo eran contrapuestos en todo, incluso en la forma de comportarse los hombres que habían alcanzado su posición gracias al mérito en contraposición al que lo había logrado por el favor ${ }^{33}$. Junto al mérito, otro de los pilares fundamentales para estos militares era el honor. Baste citar como ejemplo la manera en que reaccionaron ante un artículo de El Castellano. En él, se protestaba por la obligación del pueblo de dar alojamiento a las tropas (y, ya de paso, La España Militar pedía al gobierno que solucionase ese problema cuanto antes). El Castellano decía que tropa y soldados entraban en las casas y acababan con toda provisión, incluso se sobrepasaban con las mujeres, inutilizaban muebles... "RARO"34 era el militar que se ajustaba a lo que mandaba la probidad y la honradez. La España Militar calificaba esas palabras de sandeces y mentiras inventadas sin prueba alguna. Se mostraban indignados con este artículo, y no era para menos, puesto que habían puesto en duda el honor y la disciplina del ejército, pintándole como aves de rapiña: “¿Si querrá este señor asimilarnos á [sic] la hez de los presidiarios?". Hasta ellos reconocían la dureza de su artículo pero la justificaban porque habían atacado lo más sagrado del ejército y lo habían hecho de forma vil, basándose en calumnias y noticias falsas que no podían probarse. Este artículo es una buena muestra de la reacción que tenían los militares cuando se les acusaba de faltar al honor y a la disciplina ${ }^{35}$.

Otra cuestión que seguía preocupando a este medio era la política de ascensos. En un artículo titulado "Anomalías" criticaban duramente, por ser lesivo para el ejército, que se recompensase a los oficiales con empleos en Armas que le eran ajenas. Así, un capitán de Ingenieros podía ser recompensado con el empleo de comandante de Infantería. Esto lo calificaban de "espantosa anomalía" y de "cosa tan ridícula". Un ingeniero no podía ser comandante de Infantería, ya que este debía ser "infante desde la suela de sus botas hasta el pompón de su morrión". El oficial de Ingenieros tenía estudios superiores al de Infantería, estaba mucho más especializado pero no podía mandar un Arma que no conocía, no tenía la instrucción ni las dotes para ejercer ese puesto, para mandar ni siquiera una compañía, "dotes que, si bien mirados con desprecio por el oficial facultativo desde la alta esfera de

31 La España Militar, 01 de febrero de 1842, pp. 1-4.

32 La España Militar, 15 de febrero de 1842, p. 42.

33 La España Militar, 15 de abril de 1842, pp. 125-128.

34 En mayúsculas en el original.

35 La España Militar, 15 de abril de 1842, pp. 144-145. Otros ejemplos de lo que significaba el honor para ellos en la entrega del 15 de junio de 1842, pp. 233-234. 
sus matemáticas trascendentales, no se reemplazan con tablas logarítmicas". Reconocían que realmente estos cargos eran solo nominales, no efectivos, pero entonces preguntaban para qué servían: ¿recompensar el mérito en un Cuerpo en el que solo se ascendía por antigüedad? ¿Necesidad de emulación? No sabían qué responder, tan solo les parecía que "esta diferencia, que para el método de ascensos existe entre las armas fundamentales del ejército y las auxiliares que tan rara como impropiamente se apellidan esclusivamente [sic] facultativas, además de irracional y absurda, es altamente injusta, [...]".

Tampoco estaban de acuerdo con el sistema de ascensos por antigüedad (porque no se premiaba con el ascenso a los mejores, sino a los más antiguos) y les parecía injusto: los ascensos debían ser iguales en todo el ejército. Pedían observar a los ejércitos extranjeros (aunque no citaban países ni mostraban ejemplos) ${ }^{36}$.

Otra muestra de continuidad entre las dos publicaciones es un artículo titulado "De las cruces" en el que denunciaban la pérdida de valor y prestigio de uno de los elementos fundamentales que existían para excitar "el espíritu belicoso", para desarrollar la virtud de un ejército, "y en fin uno de los más preciosos artículos de fe del culto militar: las cruces". La multiplicidad, la prodigalidad y desconsideración que rodeaban a este mundo estaba haciendo que desapareciese en breve tiempo. Cada vez había más cruces y estas se otorgaban con mayor arbitrariedad, por tanto este medio denunciaba que así nadie estaba condecorado (porque todos tenían cruces) y se habían confundido los grados porque había tantas que no se sabía qué significaban, ayudando al desprecio generalizado de todas ellas. Alguna se mantenía con su prestigio intacto: la cruz de San Fernando de $2^{\mathrm{a}}$ clase -la laureada-por ejemplo, pero había otras que la imitaban en apariencia, confundiéndose y reduciendo, por tanto, su valor ${ }^{37}$.

El 1 de diciembre de 1842 se anunciaba la publicación de la serie segunda de La España Militar. Nada tendría esto de extraño de no ser porque el mismo medio anunciaba que cambiaba de manos. A partir de ese momento, el redactor propietario desde ese momento sería Ramón Halliday. El periódico reducía sus páginas, pasando de dieciséis a ocho pero, a cambio, su periodicidad sería semanal. Además, desaparecían las láminas y dibujos con los que solía concluir sus entregas este medio. Sin embargo, la temática no variaba mucho. Así, en marzo de 1843 se daba publicidad a las quejas de muchos militares por el retraso en el pago de salarios. A los oficiales se les pagaba por mitades o por tercios, algo que se había constituido en regla general y que no gustaba a nadie por los abusos que se cometían. Un alférez o teniente no podía vivir dignamente con una paga entera, que tan solo le permitía atender sus necesidades, como para vivir con mitades o tercios. Muchos acudían al juego para ganar dinero y generalmente lo perdían. El coronel, el comandante y el capitán podían hacer frente a los gastos de un mes, como mínimo, con su paga completa. Estos también la percibían con retraso pero el subalterno no podía permitirse eso; así, acababan presentándose en público como mendigos, con el desprestigio que tenía eso para el ejército. Pedían justicia a los jefes para acabar con esa situación tan penosa de los subalternos ${ }^{38}$. Meses antes, en su entrega del 15 de diciembre, este medio denunciaba que en otros países premiaban a los militares, les recompensaban, les tenían estima y consideración. En España no, en nuestro país el militar licenciado se veía abocado a la mendicidad... y la culpa era del gobierno ${ }^{39}$.

36 La España Militar, 01 de mayo de 1842, pp. 149-151.

37 La España Militar, 15 de julio de 1842, pp. 282-283.

38 La España Militar, 28 de marzo de 1843, p. 241-242.

39 La España Militar, 15 de diciembre de 1842, p. 29. 
Como se puede observar, las críticas al gobierno no desaparecían, más aún, arreciaban, motivo que puede explicar por qué el 7 de abril de 1843 La España Militar se publicase por última vez.

\section{CONCLUSIONES}

Cualquier militar o civil que se aproximase a este tipo de prensa, se llevaría una imagen muy negativa sobre la situación que atravesaba el ejército español a comienzos de la década de 1840. Tanto estos medios como otros de la misma temática (y también redactados por militares) transmitían esa sensación. Sí es cierto que entre ellos surgían polémicas y desavenencias que, incluso, llegaban hasta las descalificaciones al no compartir ciertas visiones. Quizá una de las más importantes se produjo en relación al uniforme militar, mostrando, además, lo relevantes que eran para ellos las prendas militares, algo que ya ha quedado patente más arriba ${ }^{40}$.

No obstante, esto no impidió que coincidiesen en muchos puntos, especialmente aquellos que no hablaban muy bien acerca de la gestión de los políticos en materia militar. Es evidente que se trata de medios que no eran partidarios del gobierno y podemos pensar que exageraban o deformaban la realidad para alcanzar sus objetivos. Sin embargo, hay puntos comunes que sí parecen ajustarse al día a día de ejército decimonónico español. El elevado presupuesto de Guerra que, además estaba mal gestionado, aumentando el descrédito de la institución militar; las leyes de reemplazo y reclutamiento que también contribuían a esa mala imagen del ejército entre los ciudadanos; la profusión de ascensos y condecoraciones que llevaban, por un lado, al desprestigio de estas últimas y, por otro, a la macrocefalia de un ejército cuyo número de oficiales, jefes y generales sobrepasaba, con mucho, los índices recomendados; el escaso sueldo que recibían no solo los soldados sino incluso algunos oficiales; la arbitrariedad y la continua interferencia de los partidos políticos; la necesidad de reformas ya que, por citar un ejemplo, aún continuaban vigentes las Ordenanzas de Carlos III, promulgadas en el año 1768. A la luz de ciertos estudios historiográficos, todas estas denuncias estaban justificadas y mostraban realmente la situación de los militares del momento, aunque exagerasen para obtener mayor atención y conseguir su objetivo ${ }^{41}$.

Lo que sí queda claro es que, verdad o no, exageración o realidad, ciertos militares se encontraban muy descontentos con el tratamiento hacia su profesión, su ánimo y moral estaban bajos, se sentían relegados, olvidados, incomprendidos por el resto de la sociedad que no les recompensaba por el enorme sacrificio que acaban de hacer. Su profesión, último refugio del honor, su misión como defensores de la nación, de su libertad e independencia, no eran comprendidas por el ciudadano (y político) español. Sufrían la desconsideración de una sociedad civil que veía todo aquello relacionado con la milicia como algo peyorativo.

Pese a todo, medios como este no cejaron en su empeño y se esforzaron por mejorar la instrucción de sus lectores, no mirando tanto al extranjero como otros medios, pero sí intentando enseñar y educar de forma amena a su público militar. Su misión era doble, en

40 Véase nota 24. Como ejemplos de polémicas, además de la del uniforme se pueden citar: La España Militar, 01de mayo 1842, pp. 170-172; 15 de julio de 1842, pp. 269-276; 01 de octubre de 1842, pp. 294-296; 01 de noviembre de 1842, pp. 343-346.

41 F. Fernández Bastarreche, El Ejército español..., declaraba que los oficiales (especialmente los subalternos) debían vivir a duras penas con el salario que les correspondía. ( $p .82$ y p. 96). El presupuesto también es analizado por este autor: pp. 75-80, al igual que las necesidades de reforma que nunca llegaban (pp. 80-81) o la macrocefalia: (p. 36), lugar común en la historiografía junto a la intervención en política o la pésima situación en que se encontraba el ejército español decimonónico, véase G. Cardona, El problema militar en España, Madrid, Historia 16, 1990. 
primer lugar porque tenían los medios para expresar la voz de muchos, para denunciar su penosa situación, por lo que no dejarían de señalar los errores que se estaban cometiendo con su profesión y buscar sus soluciones y, en segundo lugar, trataron de mejorar el nivel de instrucción de los soldados y oficiales, mostrándoles a ellos y al resto de la sociedad que el ejército se componía de hombres instruidos, honrados y valientes, que no dudaban en dar su vida por su país, por lo que no merecían indiferencia o desprecio sino respeto y admiración de quien actúa como pilar fundamental que mantenía en pie la nación compartida por todos.

\section{FUENTES}

Gaceta, núm. 2498, 19/08/1841.

Diario de Sesiones del Congreso, Congreso de los Diputados, núm. 53, 27/05/1841.

Diario de Sesiones del Congreso, Congreso de los Diputados, núm. 54, 28/05/1841.

Diario de Sesiones del Congreso, Congreso de los Diputados, núm. 141, 17/08/1841, pp. 3174-3176.

\section{FUENTES HEMEROGRÁFICAS}

El Archivo de los Militares, Madrid, Biblioteca Nacional de España, 28 de junio de 1843.

El Archivo del Ejército, Madrid, Biblioteca Nacional de España, 4 de junio de 1843-17 de junio de 1843.

El Archivo Militar, Madrid, Biblioteca Nacional de España, 1 de abril de 1841-26 de agosto de 1841 y 6 de abril de 1842-22 de abril de 1843.

Archivo Militar: Colección de las leyes, reales decretos, órdenes, reglamentos, circulares y resoluciones generales espedidas [sic] por el Ministerio de la Guerra, Madrid, Biblioteca Nacional de España, 1 de enero de 1839-31 de diciembre de 1846.

El Archivo Militar. Sección Militar, Madrid, Biblioteca Nacional de España, 2 de septiembre de 1841-31 de marzo de 1842.

El Archivo Militar. Sección Política, Madrid, Biblioteca Nacional de España, 7 de septiembre de 1841-29 de marzo de 1842.

El Estandarte, Madrid, Biblioteca Nacional de España, 1845.

El Grito del Ejército, Madrid, Hemeroteca Municipal de Madrid, marzo de 1841-20 de diciembre de 1841.

La España Militar, Madrid, Biblioteca Nacional de España, 1 de febrero de 1842- 7 de abril de 1843.

\section{BIBLIOGRAFÍA}

Aguilar Olivencia, M., "Historia del periodismo español. Escasas fuentes de investigación al tratar de periodismo militar", Ejército, (1980).

- "Los orígenes de la prensa militar española", Reconquista, 339, (1978), pp. 58-59.

- "Prensa de las clases pasivas en las Fuerzas Armadas", Tierra, Mar y Aire, 118, (1979), pp. 25-26.

- $\quad$ "Prensa de otros tiempos: Almanaque del Guardia Civil", Vida Benemérita, 8, (1979), pp. 31-33.

- "Ese gran desconocido en España (I). El periodismo militar", Diario 16, (1979).

- $\quad$ "Ese gran desconocido en España (y II). El periodismo militar", Diario 16, (1979).

Cardona, G., El problema militar en España, Madrid, Historia 16, 1990.

Checa Godoy, A., Censo de la prensa española editada durante el reinado de Isabel II (1843-1868), Sevilla, Padilla, 2018.

- Censo de la prensa española en los inicios del Régimen Liberal (abril 1833-julio 1843) y relación de periodistas y fuentes, Sevilla, Padilla, 2018. 
- El ejercicio de la libertad. La prensa española en el Sexenio Revolucionario (18681874), Madrid, Biblioteca Nueva, 2006.

El Argonauta español: "La Presse militaire. Naissance et évolution d' un genre", 10, (2013). Disponible online: https://journals.openedition.org/argonauta/1588 (Fecha de consulta: 08-10-2020).

Fernández Bastarreche, F., El Ejército español en el siglo XIX, Madrid, Siglo XXI, 1978.

González-Pola De La Granja, P., La configuración de la mentalidad militar contemporánea y el movimiento intelectual castrense. El siglo crítico 1800-1900, tesis doctoral, Madrid, Universidad Complutense, 2002.

Gutiérrez De Quijano, P., Biografía de don Luis Corsini y Fontaine, Madrid, Gráfica Universal, 1933.

Payne, S. G., Los militares y la política en la España Contemporánea, París, Ruedo Ibérico, 1968,

Pinto Cebrián, F., Ejército e historia. El pensamiento profesional militar español a través de la literatura castrense decimonónica, tesis doctoral, Valladolid, Universidad de Valladolid, 2011.

Shubert, A., Espartero, el Pacificador, Barcelona, Galaxia Gutenberg, 2018.

Silvela Díaz-Criado, E., El proceso de profesionalización del Ejército en España: El Cuerpo de Estado Mayor, 1810-1932, tesis doctoral, Madrid, Universidad Nacional de Educación a Distancia, Instituto Universitario General Gutiérrez Mellado, 2015.

Vanaclocha Bellver, F. J., Prensa político-militar y sistema de partidos en España (18741898), Madrid, Fundación Juan March, 1981. 